\title{
Auch Gentests ändern nichts am Lebensstil
}

\author{
Wer per DNA-Analyse ein Risiko für eine genetisch determinierte Krankheit entdeckt, \\ aktuell aber noch gesund ist, ignoriert Empfehlungen zu Verhalten und Vorsorge.
}

_ DNA-Analysen decken heutzutage erhöhte Risiken etwa für bestimmte Karzinome und kardiovaskuläre Erkrankungen, für Diabetes, familiäre Hypercholesterinämie oder Morbus Crohn frühzeitig auf. Vorbeugemaßnahmen wie Rauch- und Alkoholverzicht, Diät, körperliche Aktivität, Lichtschutz und regelmäßige Kontrolluntersuchungen sind dann angeraten.

18 randomisierte Studien beschäftigten sich mit Menschen, bei denen per DNA-Tests ein hohes Risiko für eine der genannten Erkrankungen entdeckt wor- den war. Viele Probanden waren für Vorsorgemaßnahmen geeignet, 73 etwa für Lichtschutzmaßnahmen und 2.663 für einen Rauchverzicht. Doch wurden diese nicht in höherem Maße realisiert als bei Kontrollpersonen, deren Risiko herkömmlich bestimmt worden war.

- Hollands GJ et al. The impact of communicating genetic risks of disease on riskreducing health behaviour: systematic review with meta-analysis. BMJ. 2016;352:i1102

\section{KOMMENTAR}

Jeder kann heutzutage online eine DNAAnalyse zur Bestimmung zahlreicher Krankheitsrisiken in Auftrag geben. Auch wird viel über Vorsorgeuntersuchungen und prophylaktische chirurgische Eingriffe bei familiärer Häufung von Mamma-, Ovarial- oder Kolontumoren berichtet - ohne dass durch kontrollierte Studien der Umfang des Erfolgs nachgewiesen wurde.

Gesundheitspolitisch effektiver ist die Vorbeugung durch Lebensstiländerungen bei weit verbreiteten Krankheiten. Doch hier vermittelt die vorliegende Studie ein ernüchterndes Ergebnis: Die Umsetzung bleibt auch mit DNATests schlecht. Diese sind bisher also ein $\mathrm{Ge}$ schäft ohne gesundheitlichen Nutzen.

Prof. Dr. med. H. Holzgreve

\section{Rötungen und Beläge wandern über die Zunge}

Dem Hausarzt war die Zunge eines 73-jährigen Mannes aufgefallen, weil sie eine ungewöhnliche Rötung aufwies, die sich in den letzten drei Monaten immer wieder verändert hatte. Der Ex-Raucher wurde wegen Hypertonie, Hypercholesterinämie und Hyperurikämie behandelt. Bei der Untersuchung erkannte man eine scharf begrenzte, flache Rötung der Zunge im Bereich des hinteren Drittels links (Abb. A). Man stellte die Diagnose einer Lingua geographica, bekannt auch als gutartige migratorische Glossitis, die mit der Raucheranamnese gut vereinbar war.

Die Lingua geographica betrifft etwa $2 \%$ der Bevölkerung. Es handelt sich dabei um einen lokalen entzündlichen Prozess mit fehlender Differenzierung der filiformen Zungenpapillen. Die Patienten berichten über gerötete Zungenareale mit scharf begrenztem weißlichen Rand, die sich kurz- fristig verändern können. Bei Verlaufskontrollen nach 8 (Abb. B) und 20 (Abb.C) Monaten stellten sich die Veränderungen anders dar. Die weißlich verdickten Ränder waren gut zu erkennen. Bei der letzten Kontrolle war auch noch eine Fissur aufgetreten. Auch nach 32 Monaten waren die Veränderungen noch vorhanden.

Die Lingua geographica ist in der Regel asymptomatisch, manche Patienten berichten aber über Schmerzen und Zungenbrennen, das durch saure und scharfe Speisen verstärkt wird. Eine Behandlung ist über eine Beruhigung des Patienten hinaus nicht erforderlich.

Prof. Dr. med. H. S. FüeßI

- Varoni E, DecaniS (elena.varoni@unimi.it):Geographic tongue. N Engl J Med. 2016;374:670
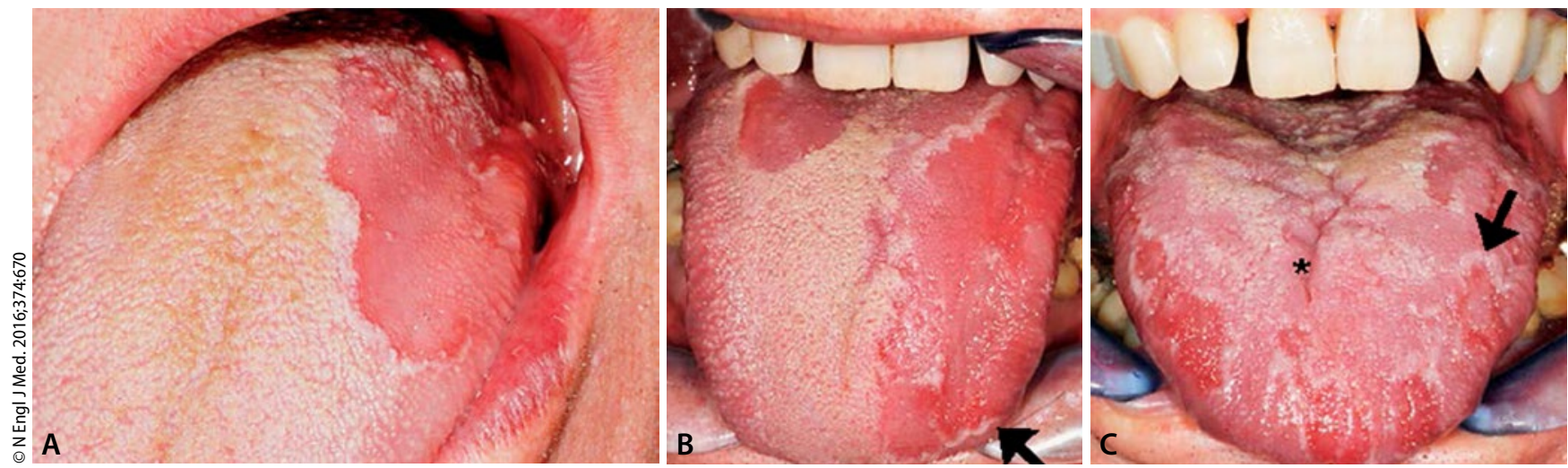

A: Scharf begrenzte, flache Rötung der Zunge. B: Befund nach 8 Wochen mit weißlich verdickten Rändern (Pfeil). C: Befund nach 20 Wochen mit verdickten Rändern (Pfeil) und Fissur (Sternchen). 